\section{AS UNIVERSIDADES INGLESAS NO CONTEXTO DA METAMORFOSE DO ENSINO SUPERIOR NAS SOCIEDADES CONTEMPOANNEAS}

\section{The English universities in the context of the metamorphosis of higher education in contemporary societies}

COLLINI, Stephan. (2018), Speaking of universities, Verso, Londres.

\section{Carlos Benedito Martins (1)}

E-mail: Carlosb@unb.br

(1) Professor Titular do Departamento de Sociologia da

Universidade de Brasília, Brasília, SP, Brasil.

Foi Visiting Professor, nas Universidades de Columbia, Oxford, Unversity College London, Universidade Nacional de Hong Kong e Universidade Nacional de Cingapura. DOI: $10.1590 / 3610614 / 2021$

O ensino superior contemporâneo, em nível internacional, encontra-se imerso em um turbilhão de profundas transformaçôes sociais, políticas, econômicas e culturais que perpassam as sociedades contemporâneas em ritmos e formatos diversos. As mudanças em curso, nas diferentes esferas, têm sido impulsionadas pelo processo de globalização que tem conectado uma pluralidade de sociedades nacionais. $\mathrm{O}$ processo de globalizaçáo _. compreendido como um fenômeno que opera tanto nos níveis macro, quanto micro, e que comporta uma dimensão multidimensional, ou seja, econômica, política e cultural , cujas manifestaçóes tornaram-se mais visíveis socialmente, a partir das últimas décadas do século passado, tem impactado o ensino superior e, especialmente, a cultura acadêmica no interior das universidades, em várias partes do mundo. (WAJCMAN, 2015; ROSA, 2013; TURNER

Resenha recebida em: 20/08/2020 Aprovado em: 01/09/2020
\& KHONDKER, 2010; TOMLINSON, 2007; APPADURAI, 2015).

Neste cenário, ocorreu, nas últimas décadas, a formação de um espaço transnacional do ensino superior, por meio da relação recíproca de uma constelação de fenômenos. Inicialmente, deve-se destacar, na constituição deste espaço, uma forte expansão do ensino superior, nos cinco continentes, em função da centralidade da produção do conhecimento nos processos econômico e social, de tal modo que, neste contexto, operam milhares de instituiçôes que absorvem milhões de alunos em seus cursos. Simultaneamente, ocorreu um significativo processo de mobilidade internacional de estudantes, de modo que aproximadamente sete milhôes de estudantes já deixaram seus países, em busca de universidades estrangeiras. Ao mesmo tempo, constata-se a emergência de rankings globais, que têm intensificado a competitividade por prestígio acadêmico entre as universidades, e entre seus respectivos países. Seus resultados têm impulsionado a corrida pelo estabelecimento de world class university; ou seja, da universidade de padrão mundial, que, na percepção de uma ampla parcela de atores que atuam neste espaço, é identificada pelo modus operandi das instituiçóes com posições destacadas nos referidos rankings. Este espaço transnacional comporta também a atuação de organismos internacionais, como Banco Mundial, Organização para a Cooperação e Desenvolvimento Econômico, Unesco, Organização Mundial do Comércio, que têm enfatizado, em seus documentos, um enfoque instrumental para o ensino superior, na medida em que concebem que sua função prioritária é contribuir para o crescimento econômico, cujas agendas de trabalho tendem a repercutir, direta e/ou indiretamente, nos sistemas nacionais de ensino superior e no interior de suas universidades. Neste espaço, verifica-se, ainda, a ação de empresas comerciais de serviços educacionais que operam em diversos países, como Grupo Lureate; a U21 Global, que representa um consórcio formado por 17 universidades estrangeiras, que oferecem cursos a distância na área de comunicação empresarial e mídia social para os cinco continentes; assim como a participação do grupo Thomson Reuters, que mantém o sistema Web of Science, e opera como uma das maiores empresas no mercado editorial de livros universitários. $\mathrm{Na}$ conjuntura da 
globalização, tal como ocorre com os fenômenos econômicos, culturais e políticos, o ensino superior não se restringe tão somente às fronteiras das sociedades nacionais. Ele tende a operar além dos seus limites territoriais. (MARTINS, 2015; MARGINSON \& KING, 2011; TURNER \& ELLIOT, 2012). Neste sentido, os processos sociais, econômicos, culturais, bem como o conjunto de valores que circulam neste espaço transnacional, tendem a reverberar, direta e/ou indiretamente, nos diversos sistemas nacionais de ensino superior e no interior de suas instituições. ${ }^{1}$

Entre as transformaçóes recentes do ensino superior internacional, constata-se, também, o surgimento de um novo léxico para se referir às universidades -. produzido por organizaçóes internacionais, como OCDE, Banco Mundial, Unesco e por determinados pesquisadores. Esses novos termos atribuídos à vida acadêmica poderiam ser considerados inusitados, até tempos atrás; tais como: knowledge society, entrepreneurial university, knowledge economy, accountability, cross-border higher education, branch campuses, ranking and league tables, world class university, etc. (AMARAL, 2018). Este novo vocabulário e outros termos congêneres passaram a ser divulgados e internalizados, em escala global, por uma multiplicidade de atores, tais como administradores de universidades, policy makers e pesquisadores nas ciências sociais, como se fossem construçóes intelectuais neutras e objetivas, cuja utilização acrítica tem contribuído para colonizar suas estruturas mentais e ações. As categorias de pensamento contidas neste vocabulário têm favorecido a construção de um "novo espírito" para as universidades; ou seja, fornecem um conjunto de atributos e valores que passam a (re)definir sua identidade institucional, procurando acentuar a competitividade tanto no interior das instituiçóes, quanto entre elas e seus respectivos países, em termos de busca de reconhecimento simbólico e social, e também, por fundos de pesquisa e financiamento. ${ }^{2}$

Numa linguagem elegante e com fina ironia, o livro Speaking of Universities capta, de forma minuciosa, as mutaçóes ocorridas, nas últimas décadas, nas universidades inglesas, salientando o impacto da adoção de políticas neoliberais por órgãos governamentais em sua reconfiguração, inserindo seu trabalho no âmbito de tendências gerais que perpassam o ensino superior no plano internacional.

O autor da obra em questão, Stefan Collini, é crítico literário, professor de literatura inglesa na Universidade de Cambridge, com trabalhos expressivos no campo da história intelectual, como Absent Minds; Intellectuals in Britain; Common Reading: Critics, Historians, Publics; What Are Universities For?, entre outros. Ele tem assumido uma posição enfática na defesa da autonomia institucional da universidade pública e exposto, de forma recorrente, suas reflexões críticas sobre o tema, em revistas e jornais, como The Times Literary Supplement, The Nation e London Review of Books. Seu livro parte do pressuposto de que, por mais de 150 anos, as universidades foram influenciadas pela concepção formulada por Humboldt, que institucionalizou o princípio da autonomia das universidades e dos docentes, como um dos seus eixos centrais enquanto condição necessária para a realização de trabalho intelectual fértil em diferentes áreas do conhecimento. Para Collini, durante este período, as universidades não deixaram de interagir com demandas práticas advindas de governos locais e nacionais, bem como provenientes do campo econômico. No entanto, procuraram preservar a identidade institucional $\mathrm{da}$ universidade, visando delinear o funcionamento de suas atividades como um espaço relativamente autônomo diante de pressóes externas, afirmando sua missão e seu compromisso com a produçâo de novos conhecimentos, independentemente de quaisquer outros propósitos práticos. (SCHULTHEIS \& ESCODA, 2008; WARD, 2012). O trabalho destaca a existência de uma constante tensão entre a expectativa de governos, agentes econômicos e parte da mídia, no sentido de que as universidades forneçam produtos práticos para a sociedade, cuja aspiraçáo tem colidido com seu compromisso institucional de desenvolver uma livre investigação pautada por critérios intelectuais. Como consequência das mudanças nos processos produtivos e nos avanços tecnológicos, desde os anos 1980 as universidades, em vários países, passaram a manter maior proximidade com a lógica do mundo econômico, seja em sua vertente comercial, empresarial ou de finanças. Em função das relaçóes que as universidades mantêm com corporaçóes econômicas e com distintas agências governamentais, para a obtenção de fundos financeiros 
adicionais para suas atividades, suas agendas de ensino e pesquisa ficaram, de certa forma, mais permeáveis às possíveis interferências destes atores. ${ }^{3}$

$\mathrm{Na}$ medida em que, nas últimas décadas, o governo inglês substituiu o financiamento público por um sistema de cobrança de taxas escolares, como condição ao acesso dos estudantes às instituiçôes de ensino superior, o livro ressalta que uma parte expressiva do debate público sobre as universidades gravitou em torno desta questão. No entanto, sublinha que, neste período, ocorreram, simultaneamente, mudanças significativas nas universidades inglesas em suas formas de gestão, governo interno, avaliação dos docentes, financiamento de pesquisa, etc., que alteraram de forma significativa as condiçóes de trabalho dos docentes, abalando o sentido de identidade que eles conferem às suas atividades acadêmicas. Como essas mudanças foram gradativas e, de certa forma, mais difíceis de serem observadas pelo grande público, elas não mereceram destaque nos meios midiáticos, tal como ocorreu com a questão da nova modalidade do financiamento do ensino para os estudantes. Os procedimentos e os sistemas de crenças do new public management (POLLIT \& BOUCKAERT, 2004), que vinham sendo utilizados em outras instituições públicas inglesas, foram igualmente introduzidos nas universidades, neste momento, com vistas a monitorar o desempenho dos docentes, desenvolver sistemas de auditoria, enfatizar objetivos de eficiência na produtividade acadêmica, e centralizar as decisóes da universidade no topo da administração. ${ }^{4}$

Para Collini, a cultura do new public management gerou uma obsessão pela busca contínua de informaçóes métricas e coleta constante de dados quantitativos a respeito da performance de produtividade dos docentes, bem como do impacto extra-acadêmico de suas pesquisas, enquanto uma finalidade em si mesma, cujos procedimentos, em sua visão, não conseguem captar aspectos essenciais da vida acadêmica, tampouco desvendar a qualidade intelectual das atividades de ensino e pesquisa. Ele assinala que as universidades inglesas possuem uma tradição secular de prática de um autogoverno, comandado pelos próprios docentes, que vem sendo eliminada e substituída, nas últimas décadas, pela contratação de quadros de gestores profissionais que assumem postos de comando na administração das universidades. Em sua perspectiva, o que define a cultura gerencial é a implantação de procedimentos, valores e interesses específicos dos administradores das universidades e/ou de agentes governamentais, geralmente pautados por uma lógica de accountability, diante dos recursos utilizados e resultados alcançados, que tende a conflitar com as especificidades das culturas acadêmicas produzidas ao longo do tempo pelos docentes. Neste sentido, o autor aponta para medidas que vêm sendo executadas pelos gestores universitários, como a dissolvição de departamentos que são considerados pouco atrativos para estudantes e, portanto, escassamente lucrativos para as instituiçóes, propondo inseri-los em estruturas acadêmicas mais amplas, tais como centros interdisciplinares, ou em outras faculdades ou institutos. A política de financiamento de pesquisa por meio de dotaçóes de recursos de longo prazo, adotada até décadas atrás, nas universidades inglesas _e considerada por Collini como condição que favoreceu a realização de um trabalho intelectual profícuo .., foi alterada por uma nova modalidade de distribuiçáo de recursos, que privilegiou a obtençấo de fundos por um período limitado de tempo, em geral, captados para a realização de projetos específicos, cuja aquisição envolve uma concorrência entre os departamentos, no interior da instituição e/ou entre universidades. Esta prática vem sendo adotada pela crença de que o princípio da competição entre departamentos e/ou instituiçóes pode aumentar a eficiência de desempenho acadêmico e impulsionar a qualidade dos estabelecimentos de ensino superior. Cada vez mais, os docentes são estimulados a captar subsídios externos para suas pesquisas e, consequentemente, para as universidades, como parte de seu trabalho acadêmico, devendo, portanto, desenvolver um self empreendedor. Os contratos de trabalho que preveem a estabilidade na carreira docente vêm sendo considerados, pelos gestores, como ineficazes do ponto de vista institucional, uma vez que constituem um obstáculo para formação da competição no mercado acadêmico, e também um empecilho para celebrar acordos trabalhistas temporários. Na visão do autor, isso consequentemente acarreta uma precarização da profissão acadêmica. $\mathrm{O}$ livro acentua o impacto dos rankings globais, que procuram classificar as mais destacadas universidades no mundo, na reconfiguração do ensino superior inglês. (JÖNS \& HOYLER, 2013). Por sua vez, critica severamente os procedimentos 
metodológicos destes rankings, que, em sua visão, apreendem de forma superficial a extensa e complexa diversidade de formatos e vocaçóes acadêmicas em âmbito mundial, e assinala que seus resultados são influenciados pelas classificaçóes anteriores. Apesar das avaliaçóes críticas aos procedimentos adotados, expostas em uma bibliografia pertinente, eles orientam as percepçóes e açóes de uma pluralidade de atores envolvidos com o ensino superior, como dirigentes de instituiçóes, policy makers, empresas comerciais de serviços educacionais, e meios de comunicação que aderem às métricas de performance de êxito acadêmico alardeado pelos rankings. A crença em seus resultados contribui para impor a amplos segmentos do ensino superior e às diversas sociedades nacionais, como modelo legítimo, as universidades de pesquisa, lideradas por instituiçôes norte-americanas que, tradicionalmente, têm ocupado as posiçóes de destaque nesses rankings. Nesta direção, a divulgação dos seus resultados desperta a atençáo de governos nacionais e de dirigentes de universidades, pelas atividades de ensino, pesquisa, recrutamento de docentes e estudantes, infraestrutura e modos de gestão adotados nas instituições que galgaram posiçôes de prestígio nos rankings globais, bem como a disposição de introduzir tais padróes acadêmicos em seus sistemas de ensino. ${ }^{5}$

Para Collini, o discurso oficial sobre ensino superior na Inglaterra tem sido, desde 1970, colonizado por uma linguagem econômica, não derivada propriamente da teoria econômica, mas proveniente de vocabulário produzido por escolas de administração, consultores de negócios e jornalistas especializados em questóes financeiras. A sociedade britânica tem sido objeto de uma deliberada campanha iniciada por think thanks ligadas a interesses do mercado econômico e por líderes empresariais e setores de direita _, que procura imprimir a lógica do mundo empresarial à totalidade da vida social, buscando associar e avaliar as atividades da vida social, culturais e intelectuais, conforme suas contribuiçóes para o crescimento econômico.

O trabalho salienta que, nas últimas décadas, os documentos do governo enfatizaram a necessidade de sustentar um crescimento econômico como condição para manter a competitividade da Grã-Bretanha na economia global, bem como a adoção de mecanismos de mercado nas diferentes esferas da vida social, como forma de incitar a qualidade dos serviços ofertados, cuja orientação foi estendida ao ensino superior. Desde o seu estabelecimento, o University Grants Committee (UGC), composto por acadêmicos seniors, serviu como organização importante na orientação da distribuição de recursos públicos para as universidades. Até 1964, o UGC mantinha uma interlocução direta com os recursos do Tesouro (Treasury). No entanto, durante o governo trabalhista, foi criado o Department of Education and Science (DES), que passou a supervisionar o UGC, minando seu poder decisório no processo de repasse de recursos públicos para as universidades. No ano de 1989, quando foi extinto, ocorreu a criação do Universities Funding Council, integrado por membros do mundo dos negócios, que orientou a utilização dos fundos públicos das universidades, com vistas a responder às prioridades estabelecidas pelo governo, de modo a aumentar a competitividade da economia inglesa.

Com a abolição da diferenciação institucional entre universidades e institutos politécnicos, em 1992, foram criados sucessivos órgãos responsáveis pelo financiamento do ensino superior, culminando na criação do Department for Business Innovation and Skill (BIS), cujo comitê diretor, formado por sete membros, passou a ser dirigido por um empresário e contou, entre seus membros, com a presença do responsável pelo McKinsey's Global Education Practice. Estas mudanças indicaram, segundo Collini, que as universidades e a pesquisa passaram a ser orientadas, cada vez mais, a partir de uma visão proveniente do mundo dos negócios, baseada numa lógica do campo econômico, voltada para a empregabilidade dos estudantes, cuja orientação foi levada adiante tanto por governos trabalhistas, quanto conservadores. Um dos documentos produzido pelo BIS, em 2009, denominado Higher Ambitions: The Future of Universities in a Knowledge Economy, indicava que alguns estudantes aspiravam ter seu próprios empreendimentos. Nesta direção, o governo manifestava a expectativa de que o espírito da sociedade empresarial fosse incorporado em todas as universidades na Inglaterra. Foi neste contexto, no governo dos trabalhistas, em 2010, que ocorreu o surgimento de Comprehensive Speding Review, que propôs um corte drástico de fundos públicos para as atividades de ensino. Simultaneamente, foi introduzida 
a política de top-up-fees, abrindo caminho para a cobrança de taxas escolares para os estudantes, cujos valores têm variado entre 7.500 e 9.000 libras anuais, instituindo, para tanto, uma política de empréstimos reembolsáveis, administrada por fundos públicos, que tem provocado um forte endividamento dos estudantes e de suas famílias. ${ }^{6}$

O livro destaca que tais mudanças visavam introduzir mecanismos de mercado no ensino superior, com vistas a incentivar uma competição entre instituiçôes, em termos de preços fixados por elas - de cujo processo o governo procura manter distanciamento , e concorrência pela qualidade dos serviços educacionais ofertados. Como qualquer empresa, as instituiçóes de ensino e as universidades cobram seus serviços de acordo com a demanda, podendo estabelecer variaçóes de preços entre seus cursos. Os estudantes são considerados consumidores de serviços educacionais que realizam suas opçóes, em termos de avaliaçóes entre custos financeiros a serem despendidos na realizaçáo de seus cursos e cálculos de possíveis benefícios profissionais futuros, em função do reconhecimento social e simbólico do estabelecimento selecionado. Ao mesmo tempo, para sobreviver, as instituiçóes de ensino superior dependem, cada vez mais, de apreciaçoóes satisfatórias dos estudantes sobre os produtos adquiridos. A conduta de imprimir um ethos empresarial no ensino superior inglês pode ser vista também pela cobrança de taxas mais elevadas para estudantes estrangeiros, que se deslocam para ter uma formação acadêmica nessas instituições de ensino. Na última década, o número de estudantes provenientes de outros países passou de 175 mil para 300 mil, de tal forma que um em cada seis estudantes no ensino superior inglês provém de outros países, especialmente da China. Atualmente, o ensino superior é classificado como sétimo item, na indústria de exportação. Simultaneamente, várias instituiçóes inglesas possuem filiais em outros países, tal como a University Central of Lancanshire, que atua no Chipre e oferece cursos de direito, administração e algumas áreas de engenharia, cobrando uma taxa de 9 mil libras de seus estudantes. ${ }^{7}$

Visando estender a lógica de mercado a todas instituiçóes que operam no ensino superior, o governo permitiu o acesso dos estabelecimentos privados aos empréstimos públicos concedidos aos estudantes para pagamento das taxas escolares. $\mathrm{O}$ volume de recursos públicos disponíveis para instituiçóes privadas não cessou de aumentar, nas últimas décadas, passando de 5 milhóes de libras, em 2008, para um total de 100 milhôes, em 2011. Nesse mesmo período, o governo aumentou o patamar do volume de recursos públicos que as instituiçôes privadas podem receber, em termos de empréstimos para estudantes, passando de 3 para 6 mil libras. Uma única instituição, denominada Greenwich School of Management, que pertence à companhia financeira Sovereign Capital, absorveu $23 \%$ do total dos recursos públicos alocados para as taxas escolares utilizadas pelos estudantes. Em função dessa medida, o número de estudantes frequentando instituiçóes privadas algumas das quais fornecendo cursos que não foram legalmente regulamentados tem crescido de forma significativa, chegando a dobrar o seu número, em 2012. Nesta direção, ocorreu uma vertiginosa expansão de instituições privadas, várias delas de perfil for profit, de tal forma que o livro informa que 150 estabelecimentos privados oferecem cursos em diferentes áreas, número superior ao das universidades inglesas. Este cenário tem impulsionado a atuação de empresas especializadas em consultorias educacionais, como, por exemplo, a Meissa, que se propóe a oferecer estratégias de negócios, a partir de pesquisas aprofundadas para empresas e organizaçóes que pretendem operar no contexto da "indústria de educação da Grã-Bretanha”.

Uma das mais significativas transaçóes ocorridas no que o autor denomina de "indústria de educação" na Grã-Bretanha foi a aquisição, em abril de 2012, do The College of Law, pela Montagu Private Equity, pela quantia de 200 milhóes de libras. Em novembro do mesmo ano, com uma velocidade incomum nas instâncias que legislam o ensino superior, a instituição transformou-se em The University of Law. No mesmo diapasão, o Regent's College, um estabelecimento que se apresenta como "not for profit", adquiriu, em 2012, a instituição americana Education Corporation. Em menos de um ano, o Department for Business, Innovation and Skills (BIS) concedeu-lhe o status de universidade. Desde então, o Regent's University College oferece cursos, cobrando uma taxa de 14 mil libras de seus estudantes, sendo que aproximadamente 
$80 \%$ deles são provenientes de outros países. Em outro movimento indicativo do avanço da presença de instituiçóes privadas com ethos empresarial, o grupo Apolo Global Management _. um dos maiores conglomerados mundiais de ensino superior, proprietário da instituição norte-americana Universidade de Phoenix, estabelecimento de fins lucrativos e uma das maiores universidades dos EUA em número de alunos (chegou a ter 600 mil estudantes, em 2010, mas o número vem diminuindo em função de investigação de órgãos oficiais) _.. formou um consórcio com o grupo financeiro The Carlyle, para assumir o controle do BPP College, em 2009, pela quantia de 303 milhóes de libras. O consórcio transformou-se na BBP University College, que possui unidades de ensino em várias cidades inglesas, como Cambridge, Manchester, Liverpool, Londres e, também, em países da Europa, como Hungria, Bulgária, Polônia, Romênia, Malta, Eslovênia e República Tcheca.

Até algumas décadas, existiam procedimentos rígidos para uma instituição tornar-se uma universidade, sendo mais difícil ainda, se ela fosse identificada como um empreendimento comercial. Havia um estrito controle na outorga do título de universidade, e sua concessão só poderia ser autorizada pelo Privy Council. A instituição que solicitava esse título passava pela avaliação de uma universidade já consolidada academicamente .. procedimento que contribuiu para manter a reputaçáo acadêmica internacional das universidades britânicas. Este procedimento foi abolido e não há mais necessidade de obter a aprovação do Privy Council para receber o título de universidade, uma vez que uma instituição que apresente requisitos mínimos possui a liberdade para autodenominar-se como universidade, e seus estudantes, sejam eles for-profit ou não, estão habilitados a obter os empréstimos públicos para pagamento das taxas escolares.

$\mathrm{Na}$ visão do autor, a distinção entre instituições públicas e privadas, na Grã-Bretanha, vem tornando-se porosa, uma vez que, desde 2012, as universidades públicas têm recebido cada vez menos recursos diretos do governo para suas atividades de ensino, passando a depender de empréstimos concedidos aos estudantes. Como foi assinalado, os estabelecimentos privados podem obter a maior parte de seus recursos através do mesmo mecanismo de financiamento.
As metamorfoses no ensino superior, na Inglaterra, não constituem um fato isolado, uma vez que várias sociedades estão sob pressão de organismos internacionais, do campo econômico, setores da mídia e de seus governos e dirigentes de suas universidades, para realizar mudanças nos valores acadêmicos que, por um longo período histórico, sustentaram o ideal de uma educação pública. Para Collini, lamentavelmente, a Inglaterra está passando por uma experiência-piloto ao responder a esta pressão. Para ele, vários países estão assistindo às mudanças não só com sentimento de pesar, uma vez que as universidades inglesas são admiradas como modelo de excelência acadêmica, mas também com sensação de apreensão, pois receiam que políticas similares possam vir a ser implementadas em seus territórios.

O livro representa uma contribuição relevante em relação aos rumos das universidades pelo mundo, interpelando uma concepção estreita do conhecimento que vem conquistando mentes e coraçóes em escala global, privilegiando a dimensão funcional e utilitária do saber e valorizando uma formação acadêmica voltada prioritariamente a atender demandas do mercado de trabalho. Trata-se, portanto, de um trabalho que traz uma reflexão minuciosa e relevante sobre os rumos não apenas da universidade inglesa, mas também de tendências mais gerais presentes no contexto do ensino superior internacional. Num tempo em que as universidades tendem a ser avaliadas em termos de utilidade econômica, e com uma linguagem estranha aos seus afazeres, o trabalho alerta que sua identidade institucional se assenta na produção e transmissão do conhecimento, e que seus resultados devem se pautar prioritariamente pela sua qualidade e relevância acadêmica.

Sua leitura nos convida a uma reflexão sobre percursos alternativos possíveis a serem trilhados, com vistas a estabelecer um delicado e complexo equilíbrio entre a preservação da autonomia institucional e sua interação com as múltiplas demandas externas com as quais as universidades devem dialogar.

\section{Notas}

1 A respeito das relaçóes entre o processo de globalização e o ensino superior, ver Cantwell, B. \& Maldonado, A. 
(2009), "Four stories: confronting contemporary ideas about globalization and internationalization in higher education". Globalization, Societies and Education, 7 (3): 289-306; Kennedy, M. (2015), Globalizing Knowledge: intellectuals, universities and public transformation, Stanford, Stanford University Press.

2 Com relação à introdução de uma liguagem econômica e categorias correlatas no ensino superior, ver: Watson, D. (2005), Death sentences: how clichés, weasel words, and management-speak are strangling public language, Nova York, Gothan Books; Moutsios, S. (2009), "International organizations and transnational education policy". Compare: a journal of comparative and international education, 39 (4) (jun): 467-478; Streckeisen, P. (2009), "Knowledge society or contemporary capitalism's fanciest dress". Analysis and Kritik, 1:181-197.

3 Quanto à penetraçáo de valores neoliberais no interior das universidades, consultar: Tigh, M. (2019), "The neoliberal turn in Higher Education”, 73, (3): 273-284; Peters, M. \& Olssen, M. (2015), "Neoliberalism, higher education and the knowledge economy: from the free market to knowledge capitalism". Journal of Education Policy, 20 (3): 313-345; Ward, S. (2012), Neoliberalism and the global restructuring of knowledge and education, Londres, Toutledge.

4 Por volta de 1990, a noçáo de new public management surgiu no vocabulário da administraçáo pública, sinalizando que a eficiência e a qualidade de serviços realizados pela rede pública poderiam ser impulsionadas através da introduçáo de modos de gestáo praticados no setor privado. Ver, a propósito, Pollit \& Bouckaert. (2004), Public management reform, Oxford, Oxford University Press; Hood \& Colin, S. (2004), Controlling modern government, Londres, Edward Elgar. A respeito da introduçáo da cultura gerencial nas universidades, consultar: Peters, M. (2013), "Managerialism and the neoliberal university: prospects for new forms of 'open management' in higher education", in Contemporary Readings in Law and Social Justice, 5 (1): 11-26.

5 Parte expressiva da bibliografia sobre os rankings globais oscila entre uma perspectiva analítica e uma postura valorativa, sugerindo estratégias para as universidades realizarem mudanças em suas estruturas, visando ocupar posiçóes destacadas no interior dos rankings globais. A respeito desta postura, ver, por exemplo, os trabalhos de Hazelkorn, Ellen. (2014), "Reflections on a Decade of Global Rankings: what we've learned and outstanding issues". European Journal of Education, 49 (1): 12-28; e também da mesma autora (2011), Rankings and the reshaping of higher education, Londres, Palgrave. Ver, ainda, os trabalhos de Rauhvargers, A. (2014), "Where are the global ranking leading us? An analysis of recent methodological changes and new developments". European Journal of Education,
49 (1): 29-44; e (2013), Global University Rankings and their impact, Bruxelas, European University Association. Afastando-se desta postura normativa, existe uma outra vertente de trabalhos que salientam que os rankings globais assumiram na orientação de uma ampla gama de atores que circulam no espaço transnacional de ensino superior. Ver a este respeito: Espeland, W. \& Sauder, M. (2009), "The discipline of rankings: tight coupling and organizational change". American Sociological Review, 74: 63-83; Lamont. M. (2012), "Toward a comparative sociology and evaluation". Annual Review of Sociology, 38: 201-2021.

6 Parte expressiva da bibliografia sobre os rankings globais oscila entre uma perspectiva analítica e uma postura valorativa, sugerindo estratégias para as universidades realizarem mudanças em suas estruturas, visando ocupar posiçóes destacadas no interior dos rankings globais. A respeito desta postura, ver, por exemplo, os trabalhos de Hazelkorn, Ellen. (2014), "Reflections on a Decade of Global Rankings: what we've learned and outstanding issues". European Journal of Education, 49 (1): 12-28; e também da mesma autora (2011), Rankings and the reshaping of higher education, Londres, Palgrave. Ver, ainda, os trabalhos de Rauhvargers, A. (2014), "Where are the global ranking leading us? An analysis of recent methodological changes and new developments". European Journal of Education, 49 (1): 29-44; e (2013), Global University Rankings and their impact, Bruxelas, European University Association. Afastando-se desta postura normativa, existe uma outra vertente de trabalhos que salientam que os rankings globais assumiram na orientação de uma ampla gama de atores que circulam no espaço transnacional de ensino superior. Ver a este respeito: Espeland, W. \& Sauder, M. (2009), "The discipline of rankings: tight coupling and organizational change". American Sociological Review, 74: 63-83; e também, dos mesmos autores (2012), "Toward a comparative sociology and evaluation". Annual Review of Sociology, 38: 201-2021.

7 A respeito da desterritorializaçáo do ensino superior, através da instalação de filiais de universidades estrangeiras em outros países, consultar: Bjanason, S. (2004), "Borderless Higher Education", in R. King (org.), The university in the global age, Londres, Palgrave MacMillan, p. 142-164; Cunningham, R. \& Stedman, T.. (2000), The Business of Borderless Education, Canbera, Department of Employment, Education, Training and Youth Affairs; Garret, R. (2017), "International Branch Campuses: Success Factors". The Observatory on Borderless Higher Education, Albany, The State University of New York at Albany; Kosmutzky, A. \& Putty, R. (2016), "Transcending Borders and Traversing Boundaries: a systematic review of the literature on transnational offshore cross-border and borderless higher education". Journal of Studies in International Education, 20 (91): 8-33. 


\section{Referências}

AMARAL, Alberto. (2018), "Universities and the knowledge society revisited", in R. Barnett; M. Peters; P. Lang (orgs.), The Idea of University: contemporary perspectives, Oxford, Peter Lang.

APPADURAI, Arjun. (2015), Modernity at large: cultural dimension of globalization. Minneapolis, The University of Minnesota.

BJANASON, Svava. (2004), "Borderless Higher Education", in R. King (org.), The university in the global age, Londres, Palgrave MacMillan, p. 142-164.

CUNNUNGHAM, Ryan. \& STEDMAN, Tapsll. (2000), The Business of Borderless Education, Canbera, Department of Employment, Education, Training and Youth Affairs.

ESPELAND, Wendy. \& SAUDER, Michael. (2009). The discipline of rankings: tight coupling and organizational change. American Sociological Review, 74: 63-83.

GARRET, Richard. (2017) "International Branch Campuses: Success Factors". The Observatory on Borderless Higher Education, Albany, The State University of New York at Albany.

HOOD, Christopher \& COLIN, Scott. (2004). Controlling modern government, Londres, Edward Elgar.

JÖNS, Heike \& HOYLER, Michael. (2013), Global geographies of higher education: The perspective of world university rankings. Geoforum, 46: 45-59.

KENNEDY.Michael.(2015) Globalizing Knowledge: intellectuals, universities and public transformation. Stanford University Press. Stanford.

KOSMUTZKY, Anna \& PUTTY, Rahul. (2016) Transcending Borders and Traversing Boundaries: a systematic review of the literature on transnational offshore cross-border and borderless higher education. Journal of Studies in International Education, 20 (91): 8-33.

LAMONT, Michèle. 2012. Toward a comparative sociology of valuation and evaluation. Annual Review of Sociology 38, no. 1: 201-221.

MALDONADO, Alma \& CANTWELL, Brendan. (2009). Four stories: confronting contemporary ideas about globalisation and internationalisation in higher education. Globalisation, Societies and Education Vol. 7, No. 3. pp. 289-306.

MARGINSON, Simon \& KING, Roger (orgs.). (2011), "Handbook on globalization and higher education", in Edward Elgar, Northampton, Massachusetts.

MARTINS, Carlos Benedito. (2015), "Notas sobre a formação de um sistema transnacional de ensino superior", in Caderno CRH, 28 (74): 291-308.
MOUTSIOS,Stavros (2009.) International organizations and transnational education policy". Compare: a journal of comparative and international education, 39 (4) (jun): 467-478.

PETERS, Michael. \& OLSSEN, Mark. (2015). Neoliberalism, higher education and the knowledge economy: from the free market to knowledge capitalism". Journal of Education Policy, 20 (3): 313-345.

PETERS, Michael. (2013) Managerialism and the neoliberal university: prospects for new forms of 'open management' in higher education". Journal of Education Policy, 20 (3): 313-345.

POLLIT, Christopher \& BOUCKAERT, Geert (2004), Public management reform, Oxford, Oxford University Press.

RAUHVARGERS, Andrejs. (2013), Global University Rankings and their impact, Bruxelas, European University Association.

RAUHVARGERS, Andrejs. (2014) "Where are the global ranking leading us? An analysis of recent methodological changes and new developments". European Journal of Education, 49 (1): 29-44.

ROSA, Hartmunt. (2013), Social Acceleration: a new theory of modernity, Nova York, Columbia University Press.

SCHULTHEIS, Franz \& ESCODA, Marta. (orgs). (2008), Le Cauchemar de Humboldt: la réforme de l'enseignement supérieur européen, Paris, Raisons d'agir.

STRECKEISEN, Peter (2009. Knowledge society or contemporary capitalism's fanciest dress". Analysis and Kritik, 1:pp.181-197.

TIGHT, Malcon. (2019). The neoliberal turn in Higher Education" Higher Education . 73, (3): 273-284.

TOMLINSON, John. (2007), The culture of Speed: the coming of immediacy, Londres, Sage.

TURNER, Bryan \& ELLIOT, Anthony. (2012), On Society, Cambridge, Polity Press.

TURNER, Bryan \& KHONDKER, Habibul. (2010), Globalization: east and west, Londres, Sage.

WAJCMAN, Judy. (2015), Pressed for time: the acceleration of life in digital capitalism. Chicago, The Chicago University Press.

WARD, Steven. (2012), Neoliberalism and the global restructuring of knowledge and education, Londres, Toutledge.

WATSON, Don. (2005), Death sentences: how clichés, weasel words, and management-speak are strangling public language, Nova York, Gothan Books. 